chapter on electromagnetic waves under the head of "Electricity," in which the nature and chief properties of these waves and their application in wireless telegraphy are briefly discussed, paves the way for a more thoroughgoing discussion of these waves under the head of "Light." From the beginning of his study of light to the end the student should never be allowed to lose sight of the fact that light is essentially an electromagnetic phenomenon; each branch of the subject should be developed on the basis of this theory; and the intimate relationship between the optical properties of a body and its electrical properties should be constantly stressed.

There is perhaps no other branch of science in which the disparity between the point of view of the investigator and that of the elementary student is quite so great as in optics. The modern worker in this field thinks of the phenomena of light in terms of electromagnetic waves and the behavior of electrons under the influence of these waves; to the student, on the other hand, the ideas which form the working basis of the investigator in his researches are meaningless, because he has no knowledge of the theory upon which these depend or of the experimental facts which underlie them. It must be admitted that in all essentials the subject of light is taught to-day very much as it was taught fifty years ago; exactly as we might expect it to be taught if Maxwell had never lived and if the theory which we owe to him had never been suggested. It is to be sincerely hoped that the near future may witness a radical change in this respect, and that those principles which serve as the groundwork of the modern physicist and which guide him in his researches may be correspondingly stressed in our attempts to present the essential facts of optics to the student.

\section{LOUISIANA STATE UNIVERSITY}

\section{David Vance Guthrie}

\section{TRANS-PACIFIC AGRICULTURE}

WHATEVER the merits of the particular case, the coincidence between the design called
House of Tcuhu in Arizona and the Minoan Labyrinth in Crete, described in ScIENCE for June 29, page 677 , is of interest as an illustration of a large class of facts in need of the more general scientific consideration that Professor Colton bespeaks. The statement, "There are three possible explanations of the coincidence," needs to be extended. American origin and prehistoric transportation to the old world is a fourth possibility as worthy of consideration as pre-Columbian transfer from the old world to America, introduction with the Spanish conquest, or independent origins in the two hemispheres.

Several cultivated plants of American origin appear to have been carried across the Pacific in prehistoric times, such as the coconut palm, the sweet potato, the bottle gourd, the yam bean, and the Upland species of cotton. The same name for sweet potato, cumara or kumara, is used by the Indians of the Urubamba valley of southern Peru and by the Polynesians, and other plant names are similar. Moreover, since the migrations of the prehistoric Polynesians extended across the Pacific and Indian Oceans, from Hawaii and Easter Island to New Zealand and Madagascar, it is not unreasonable to look for traces of communication with ancient America in the early civilizations of Asia, Africa or the Mediterannean region.

Agriculture is the primary, fundamental art of civilization, and the evidence of the cultivated plants is the most concrete of any that bears upon the question of prehistoric communication between the more civilized peoples of the two hemispheres. No such significance can be ascribed to the contacts or migrations of non-agricultural people across Bering Strait or the Aleutian Islands. For ethnologists, it may be easy to assume that agriculture had separate beginnings in the old world and the new, but botanists are unable to believe that the same genera and species of cultivated plants originated independently in the two hemispheres, or that they were carried across the Pacific without human assistance.

Peru undoubtedly was the chief center of 
domestication and distribution of cultivated plants in America, and in view of this must be considered also as a point of convergence in attempting to trace back to their origins other features of primitive civilization. The large number of domesticated plants and the high development of agriculture in Peru testify even more forcibly than the succession of different styles of Cyclopean architecture to the presence of large agricultural populations in the valleys of the eastern Andes through long periods of time. The ancient reclamation works of Peru challenge comparison with anything that was accomplished in Egypt or Assyria. How far the influence of the ancient Peruvian civilization may have extended in America or elsewhere is a question to which atiention may well be given. Pressure of population is a compelling force in the domestication of plants and the development of intensive agriculture, as well as a cause of migration to unoccupied regions. The essential unity of physical types and of agricultural and other arts among the more advanced peoples of ancient America is to be taken into account, as well as the indicacations of early trans-Pacific communication of agricultural arts and cultivated plants.

It is important to consider all of the archeological and ethnological agreements or coincidences, since these may make it possible to determine the stage of development of civilization in which the prehistoric communication occurred. Whether any particular agreement of words, traditions, or "culture elements" is of real significance is not likely to be determined until such data are brought into relation with facts of other kinds. From the House of Tcuhu in Arizona to the Labyrinth of Minos in Crete, by the way of Peru and Polynesia, is a long journey, but it covers the most practicable routes for the gradual extension of primitive agricultural peoples. That the labyrinth design originated independently in the two hemispheres is as hard to believe as that different people should have identical thumb-prints. If postColumbian transfer from the Mediterranean region can not be shown, the trans-Pacific route from America to the old world should be considered. O. F. Coor

Bureau of Plant Industry,

U. S. Department of Agriculture, WAshington, D. C.

\section{BENJAMIN FRANKLIN AND THE STRUGGLE FOR EXISTENCE}

THE extent of Benjamin Franklin's mailing address mentioned in the contributions of Dr. Hussakoff and Professor Woodruff in recent issues of SoIENcE is equalled only by the breadth of Franklin's scientific and other interests.

Just as Darwin and Wallace arrived at the theory of natural selection by reading Malthus's essay on the "Principle of Population" so Malthus was prompted to write his essay by reading a very brief contribution of Franklin published in 1751 "Concerning the Increase of Mankind."

Franklin's clear observations on the peopling of the New World led him very surely to the notion of a struggle for existence and the pressure of population on the environment. On these two points Franklin writes as follows:

There is, in short, no bound to the prolific nature of plants and animals but what is made by their crowding and interfering with each other's means of subsistence. Was the face of the earth vacant of other plants, it might be gradually sowed and overspread with one kind only. as, for instance, with fennel, and were it empty of other inhabitants, it might in a few ages be replenished from one nation only, as, for instance, with Englishmen. Thus there are supposed to be now upwards of $1,000,000$ of English souls in North America (though it is thought that seare 80,000 have been brought over sea) and yet, perhaps, there is not one the fewer in Britain.

Regarding the pressure of population, Franklin says in this same essay that America is

chiefly occupied by Indians who subsist mostly by hunting. But as the hunter, of all men requires the greatest quantity of land from whence to draw his subsistence, the Europeans found America as fully settled as it well could be by hunters.

\section{Lafayette College}

B. W. KunkeL 